\title{
Effect of Adding Basalt Powder on Flexural Strength of a Denture Base Acrylic Resin
}

\author{
Alaa'a Mazza Salloum* \\ Professor, Department of Removable Prosthodontics, Faculty of Dental Medicine, Syria
}

*Corresponding author: Alaa'a Mazza Salloum, Professor, Department of Removable Prosthodontics, Faculty of Dental Medicine, Syria

\begin{tabular}{l}
\hline ARTICLE INFO \\
\hline Received: May 09, 2019 \\
Published: May 14, 2019 \\
\hline Citation: Alaa'a Mazza Salloum. Effect \\
of Adding Basalt Powder on Flexural \\
Strength of a Denture Base Acrylic \\
Resin. Biomed J Sci \& Tech Res 18(1)- \\
2019. BJSTR. MS.ID.003085.
\end{tabular}

Keywords: Acrylic Resin; Basalt Powder; Flexural Strength

\begin{abstract}
Poly (Methyl Methacrylate) (PMMA) is commonly used for the construction of removable partial or complete dentures because it has various advantages. However, it has also several limitations, one of these disadvantages is its poor mechanical property that causes denture base to break easily. Aim of the present study was to evaluate the effect of incorporating Basalt Powder (BP) into a conventional heat-cured acrylic resin in different concentrations on the Flexural Strength (FS) of the PMMA. A compression moulding technique was used to process 40 rectangular acrylic resin specimens (64 $\mathrm{mm}$ length $\times 10 \mathrm{~mm}$ width $\times 3.3 \mathrm{~mm}$ thickness). Specimens were equally divided into four groups according to the ratio of basalt powder added to acrylic resin: group A: $0 \%$ wt (control group), group B: $1 \% w t$, group C: $2 \% w t$, and group D: $5 \%$ wt of BP. The specimens were tested using a three-point bend test. Collected data were analyzed with One-Way Analysis of Variance (ANOVA) at significant level of 0.05 to determine whether there were any statistically significant differences between the four independent groups. ANOVA was followed by Bonferroni test to determine which groups differed from each other. Specimens reinforced by 1\% wt BP (group B) exhibited a higher mean FS compared to the control group (group A) and the two other groups. It could be concluded that adding basalt powder up to $2 \%$ wt may improve the flexural strength of the acrylic resin.
\end{abstract}

\section{Introduction}

Recently, dental implants are increasingly used in the treatment of edentulous patients, but conventional complete dentures are still the treatment of choice in many cases due to medical and financial reasons [1]. Historically, materials such as bone, wood, ivory, and vulcanized rubber were used for denture bases; but now Poly (Methyl Methacrylate) (PMMA) is commonly used for the construction of removable partial or complete dentures [2,3]. This material is frequently used because it has various advantages, including low cost, biocompatibility, ease of processing using relatively simple techniques, stability in the oral environment, and acceptable aesthetics [4,5]. In spite of its advantages, PMMA has several limitations, one of these disadvantages is its poor mechanical property that causes denture base to break easily [6]. Denture base resins should have enough strength and toughness to withstand forces generated during function and being dimensionally stable for many years under varying thermal conditions [4].
Denture base resins are subjected to a multiplicity of stresses during function. Denture fractures may be resulted from a flexural fatigue failure because of cyclic deformation of the base during function. Impact fracture, on the other hand, may result from accidental dropping of the dentures by the patients [7]. The chemistry of PMMA has developed over the years [4]. Although all of enhancements have greatly improved several properties of PMMA, it still has the inherent disadvantage of having a relatively low strength. Several attempts have been carried out to improve the properties of PMMA by using different curing methods and/ or incorporating fibers or fillers in its composition as well $[5,8,9]$. Addition of fillers and fibers to PMMA is widely used method to improve both its physical and mechanical properties [5]. These additions may include Fibers [glass fiber, polyamide fiber, polyethylene and polypropylene fibers, natural fibers], Fillers [Metal oxides: Alumina $\left(\mathrm{Al}^{2} \mathrm{O}_{3}\right)$, Zirconia $\left(\mathrm{ZrO}_{2}\right)$, Titanium Dioxide 
$\left(\mathrm{TiO}_{2}\right)$; Noble metals: Silver (Ag), Nano-Gold (Au), Platinum (Pt), Palladium (Pd); Minerals: hydroxyapatite fillers, Silicon Dioxide $\left(\mathrm{SiO}_{2}\right)$, silica-based filler; Carbon family fillers: nano-carbon, nanodiamonds], and Hybrid fiber reinforcement [10].

Singh et al. [11] demonstrated that reinforcement with $2 \%$ and $5 \%$ glass fibres showed statistically significant improvement in the Flexural Strength (FS) of the PMMA. Also, the incorporation of Aramid fibers and Oil palm empty fruit bunch (natural fibers) has been suggested to increase the FS of acrylic resin $[12,13]$. Conversely, addition of Polyethylene fibers to the acrylic resin did not have a significant effect on the transverse strengths [14].

Several studies have recommended using fillers to strengthen denture base resin [10]. Reinforcement of PMMA with metal oxides improved the physical and mechanical properties of the material [15-17]. Addition of Aluminium Oxide $\left(\mathrm{Al}_{2} \mathrm{O}_{3}\right)$ fillers to heat polymerized acrylic resin led to increased FS [18,19]. Moreover, silane-treated aluminum particles significantly increased the FS and wear resistance of PMMA [20]. On the other hand, modification of heat-cured acrylic resin with zirconia $\left(\mathrm{ZrO}_{2}\right)$ may be useful in preventing denture fractures and undesirable physical changes resulting from oral fluids clinically [21,22]. Merging zirconia nano-particles NPs was proposed to improve the mechanical properties of PMMA [23]. Incorporation of nano- $\mathrm{ZrO}_{2}$ into the repair resin improved the FS of repaired denture bases especially with high nano- $\mathrm{ZrO}_{2}$ concentrations [24]. Furthermore, using of silane coupling agent may improve the FS of PMMA/ nano- $\mathrm{ZrO}_{2}$ composite resin material of denture base plate [25]. In addition to the above, $\mathrm{ZrO}_{2}$ nanotubes had a better reinforcement effect than $\mathrm{ZrO}_{2}$ nanoparticles [26].

According to Safi [27] modifying acrylic resin by addition of Titanium Dioxide $\left(\mathrm{TiO}_{2}\right)$ in $5 \%$ by weight may lead to thermal and mechanical stability more than non-modified one. Reinforcement of PMMA with different concentrations of $\mathrm{TiO}_{2}$ nanoparticles or $3 \%$ wt of silanized $\mathrm{TiO}_{2}$ Nano particles revealed higher FS than those of normal PMMA [28,29]. In contrast, Ahmed et al. [30] concluded that incorporation of $\mathrm{TiO}_{2}$ nanoparticles into acrylic resins could adversely affect its FS. Adding Silver Nanoparticles (AgNPs) or Gold Nanoparticles (AuNPs) to PMMA significantly increased viscoelastic properties [31,32]. As well as, It was found that platinum and palladium significantly augmented the bending strength of PMMA [33]. The addition of hydroxyapatite or hydroxyapatite nanoparticles also improved the mechanical properties of the PMMA [34,35]. Mixing nano Silicon Dioxide (SiO2) powder with acrylic resin improved the transverse strength of PMMA [36]. However, Cevik and Yildirim-Bicer concluded that the silica nanoparticles ( $\mathrm{SiO}_{2} \mathrm{NPs}$ ) incorporation into acrylic resin decreased the flexural strength of the acrylic resin [37].

Multiple-Wall Carbon Nano-Tubes (MWCNTs) could be used as an effective reinforcement material for denture base resin $[38,39]$, Whereas the study of Qasim et al. [40] revealed that the effect of carbon nano tubes on flexural properties of PMMA were not statistically significant. Protopapa et al. [41] proposed to use Nano-Diamonds (NDs) to reinforce the PMMA because they found that fracture toughness of PMMA increased as the ND percentage increased up to $0.38 \%$ wt. Based on the above, several PMMA denture base resin types are available today. Their compositions are similar but small variations lead to different physical properties. Although all of these efforts to improve the acrylic resin base material, it is still not ideal in every respect, especially when meeting with mechanical requirements of prosthesis [42].

The purpose of this study was to evaluate the effect of incorporation of different concentrations of Basalt Powder (BP) into a conventional heat-cured acrylic resin on the FS of a PMMA. The null hypothesis was that there are no significant differences in the FS among the test groups of different BP concentrations.

\section{Materials and Methods}

Ethical clearance for the study was obtained from Ethical Committee of Faculty of Dental Medicine at Damascus University. A total of 40 rectangular acrylic resin specimens were fabricated. The specimens were equally divided into four groups according to the ratio of BP added to acrylic resin. Group A: 0\% wt (control group), group B: $1 \% w t$, group C: $2 \% w t$, and group D: $5 \%$ wt of BP. In according to The General Establishment of Geology and Mineral Resources in Syria, the chemical structure of the used basalt is $\left(\mathrm{SiO}_{2}: 42-47 \%, \mathrm{Na}_{2} \mathrm{O}+\mathrm{K}_{2} \mathrm{O}: 4-6 \%, \mathrm{Al}_{2} \mathrm{O}_{3}: 13-17 \%\right.$, $\mathrm{CaO}: 5-9 \%, \mathrm{MgO}$ : 7-10\%). Basalt powder used in the study was obtained from rocks in southern Syria. A power analysis (using G*Power Version 3.1.5) was performed to determine the required sample size. Heat-cured acrylic resin specimens measuring $64 \mathrm{~mm} \times 10 \mathrm{~mm} \times 3.3 \mathrm{~mm}$ were fabricated according to ISO 20795-1 [43].

Rectangular metal dies of dimensions $64 \mathrm{~mm}$ length $\times 10 \mathrm{~mm}$ width $\times 3.3 \mathrm{~mm}$ thickness were used for measuring FS. A vinyl polysiloxane putty (Vertex Castil 21, Vertex dental, Zeist, The Netherland) matrix was created from these dies. Pink base plate wax was then dripped into the matrix to form wax duplicates. A compression molding technique was applied to preparing all specimens. The wax plates were invested in artificial type III dental stone (Durguix, Hard natural stone, Protechno, Gerona, Spain) using conventional flasks. The flask was placed in boiling water for 4 to 6 minutes to soften the wax. Then it was removed from the water, and the two halves of the flask were separated. The wax is removed, and the residual wax was washed out with a stream of boiling water. After the stone was dried, the inside of the mould was painted twice with a separating medium with a camel hairbrush.

The heat-polymerized acrylic resin (Vertex Regular, Vertex dental, Zeist, The Netherland) was mixed according to manufacturer's instruction. For fabricating bazalt reinforced test specimens, the basalt filler and PMMA were pre-weighed in order to ensure a filler concentration of $1 \%, 2 \%$ and $5 \%$ by weight. Mixing and blending were done to obtain a regular and uniform mixture. The resultant mixture was then mixed with monomer. When the 
mixture reached a dough consistency, it was packed in the mould [7]. A sheet of separating plastic was applied between the stone and the acrylic resin. The flask was closed and submitted to trial packing procedure [7]. The final closure was at $24.13 \mathrm{~N} / \mathrm{mm}^{2}$ and maintained for $30 \mathrm{~min}$. The acrylic resin was polymerized in water with long polymerization cycle. The polymerizing unit (Hanau Engineering Company, Buffalo, N.Y., U.S.A.) was controlled to raise the temperature to $74^{\circ} \mathrm{C}$ at 1 hour, and then kept at $74^{\circ} \mathrm{C}$ for 8 hours. After polymerizing and cooling inside the water bath to room temperature, deflasking was carefully completed. Specimens were evaluated to ensure absence of voids or gross irregularities with $3.5 \times$ magnification. Specimens were then finished with 400 and 600-grit sandpaper. The dimensions of all specimens were checked by digital caliper, which can record changes as small as 0.01 $\mathrm{mm}$. Prior to flexural strength test, all specimens were stored in distilled room temperature water 17 days for conditioning [4]. The specimens were tested using a three-point bend test in accordance with ISO 20795-1 [43] guidelines for denture base polymers.

The three-point bending test was done by Universal Testing Machine (DY-34 ADAMEL LHOMARGY, FRANCE) at a crosshead speed of $5 \mathrm{~mm} / \mathrm{min}$ (Figure 1). The peak load (rupture load) was converted to FS by the formula: [28]

$$
\mathrm{FS}=3 \mathrm{PL} / 2 \mathrm{bd}^{2}
$$

Where FS = flexural strength $\left(\mathrm{N} / \mathrm{mm}^{2}\right) ; \mathrm{P}=$ load at fracture; $\mathrm{L}=$ distance between jig supports; $b=$ specimen width; $d=$ specimen thickness.

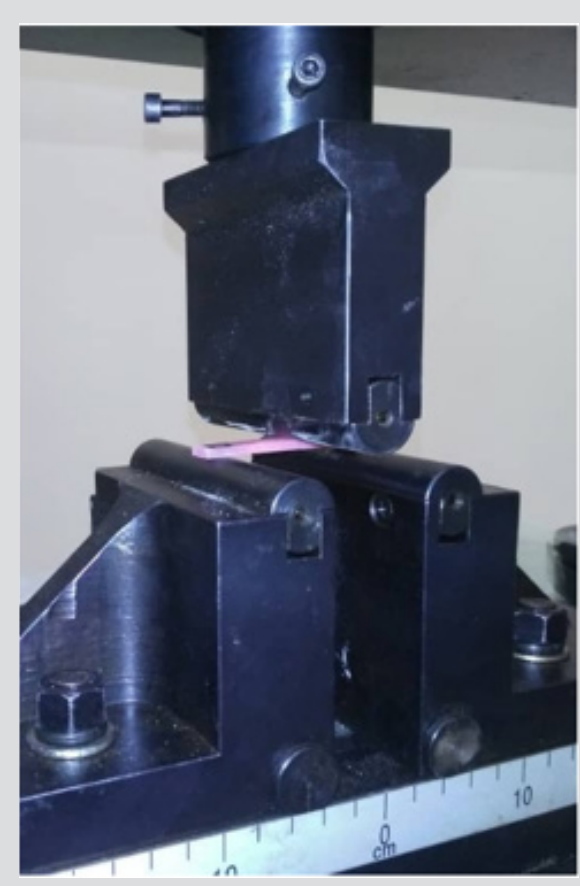

Figure 1.

Data was analyzed using statistical software (SPSS version 18.0). The One-Way Analysis of Variance (ANOVA) at significant level of 0.05 was used to determine whether there were any statistically significant differences between the four independent groups. ANOVA was followed by Bonferroni test to determine which groups differed from each other.

\section{Results}

Mean values of FS for the four test groups are illustrated in Table 1. Specimens reinforced by $1 \%$ wt BP (group B) exhibited the higher mean FS in comparison with the control group (group A) and the two other groups (group $C$ and $D)(p<0.05)$. Flexural strength of group C (specimens reinforced by $2 \%$ wt BP) was significantly more than FS of group A and D only $(\mathrm{p}<0.05)$. However, group D (specimens reinforced by $5 \%$ wt BP) demonstrated the lowest FS $(\mathrm{p}<0.05)$ (Table 2).

Table 1: Mean, standard deviation, minimum and maximum values of flexural strength (MPa) for the test groups.

\begin{tabular}{|c|c|c|c|c|c|}
\hline Groups & $\mathbf{N}$ & Mean & Std. Deviation & Minimum & Maximum \\
\hline A & 10 & 78.4620 & 3.52585 & 72.88 & 83.12 \\
\hline B & 10 & 90.5150 & 3.17103 & 84.99 & 95.55 \\
\hline C & 10 & 83.6880 & 3.30705 & 76.84 & 87.77 \\
\hline D & 10 & 73.2580 & 4.31064 & 65.22 & 78.21 \\
\hline
\end{tabular}

Table 2: Multiple comparisons (Bonferroni test).

\begin{tabular}{|c|c|c|}
\hline (I) Group & (J) Group & Mean Difference (I-J) \\
\hline \multirow{2}{*}{ A } & B & $-12.05300^{*}$ \\
\cline { 2 - 3 } & C & $-5.22600^{*}$ \\
\cline { 2 - 3 } & D & $5.20400^{*}$ \\
\hline \multirow{2}{*}{ B } & A & $12.05300^{*}$ \\
\cline { 2 - 3 } & C & $6.82700^{*}$ \\
\cline { 2 - 3 } & D & $17.25700^{*}$ \\
\hline \multirow{2}{*}{ C } & A & $5.22600^{*}$ \\
\cline { 2 - 3 } & B & $-6.82700^{*}$ \\
\cline { 2 - 3 } & D & $10.43000^{*}$ \\
\hline \multirow{2}{*}{ D } & A & $-5.20400^{*}$ \\
\cline { 2 - 3 } & B & $-17.25700^{*}$ \\
\cline { 2 - 3 } & C & $-10.43000^{*}$ \\
\hline
\end{tabular}

\section{Discussion}

Acrylic resin has been still used to fabricate approximately $95 \%$ of the denture bases [15]. It is a commonly used material in the field of prosthodontics because of its advantages such as esthetics, dimensional stability, ease in manipulation and processing [44,45]. However, it has disadvantages like reduced mechanical strength, low thermal conductivity, and high coefficient of thermal expansion [46], which make it far from being an ideal denture base material. So, several efforts are being made to improve its properties. Acrylic resin dentures fracture may be occurred primarily because of impact or fatigue failure [44]. Thus, there are usually two types of failures, first is caused due to high stresses outside the mouth (impact failure) and second is due to repeated low stresses inside the mouth (fatigue failure) $[44,47,48]$.

There are three ways to improve the mechanical properties of PMMA. These ways include replacing PMMA with an alternative 
material; chemically modifying it; and reinforcing the PMMA with other materials $[9,49]$. Also, different denture designs have been made to decrease stress such as increasing the thickness of the denture base. However, if the thickness of denture base increases, the tongue space reduces and that will affect speech adversely [50].

The current research aimed to assess possible improvements in the FS of PMMA, through incorporating BP. Three-point bending test simulates the type of stress applied to the denture during mastication, so it is used to identify the FS of a material [51]. The present study was done to compare the effect of BP addition on FS of heat cure denture base acrylic resin processed by conventional water bath technique. The results clearly revealed the highly significant increase in FS of specimens prepared by adding $1 \% \mathrm{wt}$ and $2 \%$ wt BP with p value $=0.000,0.015$, respectively $(\mathrm{p}<0.05)$ This increase in FS can be attributed to transformation toughening. When adequate stress develops and microcracks initiate to propagate, the transformation phenomenon occurs, which reduces energy for crack propagation [52]. So, a suitable distribution of the filler within the matrix can stop or deflect cracks [53].

On the other hand, the results showed that increasing the percentage of BP to $5 \%$ wt reduced the FS. This decrease in FS at higher concentration may be explained on the basis of the quality of distribution of BP. Basalt powder agglomeration may be occurred which adversely affects on the FS of the specimens. This phenomenon concentrates the stress on particular points (basalt powder) in the resin phase and spreads the crack easily through the unfilled parts of the resin matrix. This can be the main reason for crack propagation that leads to matrix fracture and reduction in FS.

Reduction in FS at higher concentration ( $5 \% \mathrm{wt}$ ) of filler may be due to a decrease in the cross-section of the load-bearing polymer matrix, stress concentration because of too many filler particles, changes in mode of crack propagation through the specimen due to an increased amount of fillers, and void formation from entrapped air and moisture $[9,18]$. The main disadvantage of adding BP to acrylic resin includes acrylic resin discoloration, it makes the acrylic resin dark and it will make the denture base unaesthetic. However, this study revealed that small concentrations of BP (1\% wt) had unimportant effect on the color of specimens. With higher concentrations, it is advisable to use BP incorporated resin in hidden areas such as lingual flanges of mandibular denture and midpalatine region of the maxillary denture.

The clinical implications of this study suggest that BP incorporation into PMMA can produce denture base resins with higher FS, provided that the ratio of BP does not exceed $2 \%$ wt. Thus, addition of BP to PMMA may have a positive effect on the longevity of complete dentures. The present in vitro study has some limitations. Only one type of acrylic resin was used and only one polymerization technique was applied. Further research is needed to understand the effect of adding BP on the mechanical properties of acrylic resin.

\section{Conclusion}

Within the limitation of the current investigation, it could be concluded that adding BP up to $2 \%$ wt may improve the FS of the acrylic resin.

\section{Acknowledgment}

I would like to express my gratitude to anyone who gave me the opportunity to complete this research. I acknowledge Damascus University for the financial support of the study. I would like to deeply thank The General Establishment of Geology and Mineral Resources in Syria for help with chemical analysis of basalt used in the research.

\section{Highlights}

a. Poly (methyl methacrylate) (PMMA) is commonly used for construction of removable partial or complete dentures.

b. Acrylic resin denture bases are vulnerable to fracture during function. So, several efforts have been made to strengthen denture base resin

c. Three-point bending test simulates the type of stress applied to the denture during mastication, so it is used to identify the flexural strength of a material.

d. It could be concluded that adding basalt powder up to $2 \%$ wt may improve the flexural strength of the acrylic resin.

\section{References}

1. Carlsson GE, Omar R (2010) The future of complete dentures in oral rehabilitation. A critical review. J Oral Rehabil 37: 143-156.

2. Boone ME (1983) New materials and techniques in Prosthodontics. Dent Clin North Am 27: 793-803.

3. Phoenix RD (1996) Denture Base Materials. Dent Clin North Am 40: 113120 .

4. Anusavice KJ (2003) Phillips' science of dental materials, (11 $1^{\text {th }}$ edn.) Elsevier Health Sciences, pp. 145-832.

5. Alla R, Raghavendra KN, Vyas R, Konakanchi A (2015) Conventional and contemporary polymers for the fabrication of denture prosthesis: Part I - Overview, composition and properties. Int J Appl Dent Sci 1: 82-89.

6. Raszewski Z, Nowakowska D (2013) Mechanical properties of hot curing acrylic resin after reinforced with different kinds of fibers. Int J Biomedical Materials Research 1(1): 9-13.

7. Zarb GA, Bolender CL, Eckert SE, Jacob RE, Fenton AH, et al. (2004) Prosthodontic treatment for edentulous patients, (12 ${ }^{\text {th }}$ edn.). Elsevier Health Sciences, pp. 576.

8. Meng TR, Latta MA (2005) Physical properties of four acrylic denture base resins. J Contemp Dent Pract 6: 93-100.

9. Jagger DC, Harrison A, Jandt KD (1999) The reinforcement of dentures. J Oral Rehabil 26(3): 185-194.

10. Gad MM, Fouda SM, Al-Harbi FA, Näpänkangas R, Raustia A (2017) PMMA denture base material enhancement: A review of fiber, filler, and nanofiller addition. Int I Nanomedicine 12: 3801-3812.

11.Singh K, Sharma SK, Negi P, Kumar M, Rajpurohit D, et al. (2016) Comparative evaluation of flexural strength of heat polymerized denture base resins after reinforcement with glass fibers and nylon fibers: An in vitro Study. Adv Hum Biol 6: 91-94. 
12. Yu SH, Ahn DH, Park JS, Chung YS, Han IS, et al. (2013) Comparison of denture base resin reinforced with polyaromatic polyamide fibers of different orientations. Dental Mater J 32: 332-340.

13. John J, Ann Mani S, Palaniswamy K, Ramanathan A, Razak AA (2015) Flexural properties of poly (Methyl Methacrylate) resin reinforced with oil palm empty fruit bunch fibers: A preliminary finding. J Prosthodont 24: 233-238.

14. Uzun G, Hersek N, Tinçer $T$ (1999) Effect of five woven fiber reinforcements on the impact and transverse strength of a denture base resin. J Prosthet Dent 81: 616-620.

15. Yadav P, Mittal R, Sood VK, Garg R (2012) Effect of incorporation of silane-treated silver and aluminum microparticles on strength and thermal conductivity of PMMA. J Prosthodont 21: 546-551.

16. Sehajpal SB (1989) Effect of metal fillers on some physical properties of acrylic resin. J Prosthet Dent 61: 746-751.

17. Vojdani M, Bagheri R, Khaledi AR (2012) Effects of aluminum oxide addition on the flexural strength, surface hardness, and roughness of heat-polymerized acrylic resin. J Dent Sci 7: 238-244.

18. Ellakwa AE, Morsy MA, El-Sheikh AM (2008) Effect of aluminum oxide addition on the flexural strength and thermal diffusivity of heatpolymerized acrylic resin. J Prosthodont 17: 439-444.

19. Arora N, Jain V, Chawla A, Mathur VP (2011) Effect of addition of sapphire (Aluminum oxide) or silver fillers on the flexural strength, thermal diffusivity and water sorption of heat-polymerized acrylic resins. Int J Prosthodont Restorat Dent 1: 21-27.

20. Chaijareenont P, Takahashi H, Nishiyama N, Arksornnukit M (2012) Effect of different amounts of 3-methacryloxypropyltrimethoxy silane on the flexural properties and wear resistance of alumina reinforced PMMA. Dent Mater J 31: 623-628.

21. Asar NV, Albayrak H, Korkmaz T, Turkyilmaz I (2013) Influence of various metal oxides on mechanical and physical properties of heatcured polymethylmethacrylate denture base resins. J Adv Prosthodont 5: 241-247.

22. Asopa V, Suresh S, Khandelwal M, Sharma V, Asopa SS, et al. (2015) A comparative evaluation of properties of zirconia reinforced high impact acrylic resin with that of high impact acrylic resin. The Saudi Journal for Dental Research 6: 146-151.

23. Safi IN, Moudhaffar M (2011) Evaluation the effect of modified nano fillers addition on some properties of heat cured acrylic denture base material. J Bagh Coll Dent 23: 23-29.

24. Gad MM, Rahoma A, Al-Thobity AM, ArRejaie AS (2016) Influence of incorporation of $\mathrm{ZrO}_{2}$ nanoparticles on the repair strength of polymethyl methacrylate denture bases. Int J Nanomed 11: 5633-5643.

25. Bian YM, Zhang XY, Zhu BS, Yu WQ, Ruan DP, et al. (2007) Influence of different amount of silane coupling agent on the flexural strength of PMMA/nanometer $\mathrm{ZrO}_{2}$ composites. Shanghai Kou Qiang Yi Xue. 16: 319-323.

26. Yu Wei, Wang X, Tang Q, Guo M, Zhao J (2014) Reinforcement of denture base PMMA with $\mathrm{ZrO}_{2}$ nanotubes. J Mech Behav Biomed Mater 32: 192197.

27. Safi IN (2014) Evaluation the effect of nano-fillers $\left(\mathrm{TiO}_{2}, \mathrm{AL}_{2} \mathrm{O}_{3}, \mathrm{SiO}_{2}\right)$ addition on glass transition temperature, E-Moudulus and coefficient of thermal expansion of acrylic denture base material. J Bagh Coll Dent 26: 37-41.

28. Harini P, Mohamed K, Padmanabhan TV (2014) Effect of Titanium dioxide nanoparticles on the flexural strength of polymethylmethacrylate: An in vitro study. Indian J Dent Res 25: 459-463.

29. Alwan SA, Alameer SS (2015) The effect of the addition of silanized Nano titania fillers on some physical and mechanical properties of heat cured acrylic denture base materials. J Bagh Coll Dent 27: 86-91.
30. Ahmed MA, El-Shennawy M, Althomali YM, Omar AA (2016) Effect of titanium dioxide nano particles incorporation on mechanical and physical properties on two different types of acrylic resin denture base. World J Nano Sci Eng 6:111-1119.

31. Mahross HZ, Baroudi K (2015) Effect of silver nanoparticles incorporation on viscoelastic properties of acrylic resin denture base material. Eur J Dent 9: 207-212.

32. Morsy MA, Al-Daous MA (2013) Mechanical properties evaluation of new AuNP-PMMA Composite. Int Rev Chem Eng 5: 65-70.

33. Aoyagi Y, Miyasaka T, Ando N (2015) Application of noble metal cluster to PMMA resin and influence on mechanical properties and color. Dent Mater J 34(6): 781-788.

34. Pan Y, Fengwei L, Xu D, Jiang X, Yu H, et al. (2013) Novel acrylic resin denture base with enhanced mechanical properties by the incorporation of PMMA-modified hydroxyapatite. Prog Nat Sci Mat Int 23: 89-93.

35. Salih SI, Oleiwi JK, Hamad QA (2015) Investigation of fatigue and compression strength for the PMMA reinforced by different system for denture applications. Int J Biomed Mat Res 3: 5-13.

36. Alnamel HA, Mudhaffer M (2014) The effect of silicon dioxide Nano-fillers reinforcement on some properties of heat-cure polymethylmethacrylate denture base material. J Bagh Coll Dent 26: 32-36.

37. Cevik P, Yildirim-Bicer AZ (2018) The effect of silica and prepolymer nano-particles on the mechanical properties of denture base acrylic resin. J Prosthodont 27(8): 763-770.

38. Somkuwar S, Mishra SK, Agrawal B, Choure R (2017) Comparison of the flexural strength of polymethyl methacrylate resin reinforced with multiwalled carbon nanotubes and processed by conventional water bath technique and microwave polymerization. J Indian Prosthodont Soc 17: 332-339.

39. Wang R, Tao J, Yu B, Dai L (2014) Characterization of multiwalled carbon nanotube-polymethyl-methacrylate composite resins as denture base materials. J Prosthet Dent 111: 318-326.

40. Qasim SB, Al Kheraif A, Ramakrishaniah R (2012) An investigation into the impact and flexural strength of light cure denture resin reinforced with carbon nanotubes. World Appl Sci J 18: 808-812.

41. Protopapa P, Kontonasaki E, Bikiaris D, Paraskevopoulos KM, Koidis P (2011) Reinforcement of a PMMA resin for fixed interim prostheses with Nano-diamonds. Dent Mater J 30: 222-231.

42. Nejatian T, Johnson A, Noort RV (2006) Reinforcement for denture base resin. Advanced Sciences and Technologies 4: 124-129.

43. ISO (2013) 20795-1, Dentistry-Base polymers.

44. John J, Gangadhar SA, Shah I (2001) Flexural strength of heatpolymerized polymethyl methacrylate denture resin reinforced with glass, aramid, or nylon fibers. J Prosthet Dent 86: 424-427.

45. Smith DC (1962) Recent developments and prospects in dental polymers. J Prosthet Dent 12: 1066-1078.

46. Darbar UR, Huggett R, Harrison A (1994) Denture fracture - A survey. Br Dent J 176: 342-345.

47. Peyton FA (1975) History of resins in dentistry. Dent Clin North Am 19: 211-222.

48. Beyli MS, von Fraunhofer JA (1981) An analysis of causes of fracture of acrylic resin dentures. J Prosthet Dent $46: 238-241$.

49. Kim SH, Watts DC (2004) The effect of reinforcement with woven E-glass fibers on the impact strength of complete dentures fabricated with highimpact acrylic resin. J Prosthet Dent 91(3): 274-280.

50. Yunus N, Rashid AA, Azmi LL, Abu-Hassan MI (2005) Some flexural properties of a nylon denture base polymer. J Oral Rehabil 32: 65-71. 
51. Kelly E (1969) Fatigue failure in denture base polymers. J Prosthet Dent 21: $257-266$.

52. Ayad NM, Badawi MF, Fatah AA (2008) Effect of reinforcement of high impact acrylic resin with zirconia on some physical and mechanical properties. Rev Clin Pesq Odontal 4: 145-151.

ISSN: 2574-1241

DOI: 10.26717/BJSTR.2019.18.003085

Alaa'a Mazza Salloum. Biomed J Sci \& Tech Res

cC) This work is licensed under Creative

Commons Attribution 4.0 License

Submission Link: https://biomedres.us/submit-manuscript.php
53. Panyayong W, Oshida Y, Andres CJ, Barco TM, Brown DT, et al. Reinforcement of acrylic resins for provisional fixed restorations. Part III: Effects of addition of titania and zirconia mixtures on some mechanical and physical properties. Biomed Mater Eng 12(4): 353-366.

$\begin{array}{ll}\text { BIOMEDICAL } & \text { Assets of Publishing with us } \\ \text { RESEARCHES } & \text { - Global archiving of articles } \\ & \text { - Immediate, unrestricted online access } \\ & \text { - Rigorous Peer Review Process } \\ \end{array}$

